\title{
Evaluating the effectiveness of a practice nurse development programme in Tower Hamlets, London
}

\author{
Christine Blunt, Richard Griffin \\ Faculty of Health and Social Care, London South Bank University, United Kingdom
}

Correspondence: Christine Blunt. Address: Faculty of Health and Social Care, London South Bank University, 103 Borough Road, London SE1 OAA, UK. Telephone: 44-207-815-6195. Email: Bluntc2@lsbu.ac.uk.

Received: December 7, 2012

DOI : 10.5430/jnep.v3n10p110
Accepted: January 23, $2013 \quad$ Online Published: April 8, 2013

URL: http://dx.doi.org/10.5430/jnep.v3n10p110

\section{Abstract}

Aim: This evaluation sought to independently evaluate the effectiveness of a Practice Nurse development programme including its impact upon capacity, access, recruitment, retention and perceived improvement for increased patient quality of care. Nurses are a significant and growing component of general practice. There is a need to support innovative education leading to increased retention and role expansion particularly in areas of high health needs.

Method: Mixed methods of comprising interviews and focus groups were undertaken and data were analysed using thematic analysis. Participants comprised of Practice Nurse trainees, General Practitioners, practice staff, programme facilitators and a programme mentor $(\mathrm{n}=21)$.

Results: Findings indicate this programme produces nurses with structured, up- to- date competence-based knowledge for effective deployment of staff.

Conclusions: This new programme can be utilised as a means of producing and retaining competent committed practice nurses whilst increasing capacity and delivering high quality care. Its approach may provide a positive future model for efficiently and speedily training practice nurses whilst increasing their competencies and depth of knowledge.

\section{Key words}

Practice nurse education, Primary care, Role development

\section{Introduction}

In the UK, the role of General Practitioners (GPs) and primary care staff has increased, particularly for managing long term chronic conditions and coordinating patient care ${ }^{[1]}$. Correspondingly, numbers of nurses employed within general practice has increased to reflect their development of areas of expertise and responsibilities ${ }^{[2-4]}$. This creates challenges for nurse managers seeking to ensure clear and appropriate boundaries between staff, effective deployment and retaining of employees and ensuring that staff have the appropriate knowledge and skills. There is however, scant research into the interventions required to achieve this ${ }^{[5,6]}$.

In 2008, NHS Tower Hamlets, (NHSTH) constructed a Practice Nurse Development programme they named 'Open Doors' with aspirations of recruiting, retaining and producing well trained nurses sympathetic to the local area health 
needs. In 2010, NHSTH commissioned London South Bank University (LSBU) to undertake an independent evaluation of the programme and this article presents the results.

\section{Background}

Tower Hamlets is one of London's smallest boroughs (a defined administrative area within the city). Densely populated, with some prosperous areas, others are amongst the poorest in England ${ }^{[7]}$. Unemployment rates are high, with a population growing faster than most of London ${ }^{[8,9]}$. Additionally, compared to other London areas, alcohol consumption, smoking and obesity are high ${ }^{[10]}$. Some chronic diseases are strongly associated with ethnicity and there is a large young ethnic community, a third of which are Bangladeshi ${ }^{[5]}$. South Asian men, for example, have a 50\% greater risk of heart attacks and older Bangladeshis' have double the risk of diabetes than other members of the population ${ }^{[5,11]}$. Tower Hamlets has also amongst the highest morbidity rates countrywide for diseases such as coronary heart or chronic obstructive pulmonary disease ${ }^{[12]}$. As such, all these factors have important implications for developing and delivering focused healthcare services in an area principally considered deprived ${ }^{[13]}$.

\section{Employment structure and profile of nurses in primary care}

The several grades of primary care nurses relate to levels of clinical decision making, instigating treatments, training and prescribing and regulated by the Nursing and Midwifery Council. Within the UK most general practice nurses (GPNs) are employed directly by general practice doctors, who are usually independent contractors rather than employees of the NHS. Contracts are not always considered as advantageous as for nurses employed by Primary Care Trusts who follow the Agenda for Change terms and conditions: the pay and grading system for most NHS workers excluding doctors ${ }^{[14]}$.

While there is a GPN competency framework aligned to the Knowledge and Skills Framework ${ }^{[15]}$ there are no specific national descriptions of practice nurse roles. Instead they are usually shaped by the practice and areas they serve. NHSTH, however, used the Working in Partnership Programme Primary Care job resources competencies to provide a framework for training ${ }^{[16]}$.

The role of GPNs has moved from basic nursing to increased expertise such as: asthma and diabetes clinics, preventative services, sexual health, immunisations and advanced clinical skills. Proportionally, consultations undertaken by GPNs have increased, and to accommodate this between 1997 and 2007 GPN recruitment has increased by $44 \%{ }^{[4]}$. Research also indicates patients are at least as satisfied with nurse consultations as doctors and higher rates of GPN consultations have been associated with better clinical outcomes in several long term conditions ${ }^{[6,17]}$.

\section{Overview of the Open Doors Nurse Programme}

The Open Doors Practice Nurse Programme was established in 2008 to train general practice nurses. This was developed in response to a study commissioned by NHSTH in 2007 (unpublished) highlighting the lack of systematic approaches to training and development of staff new to primary care. In particular, with an awareness of local service needs and the changes of job skills and roles required for primary care.

The two year programme leads to a BSc (Hons) Primary Care (Practice Nursing) degree delivered by City University, London. During training, nurses are employed by practices within the Tower Hamlets area. Led by an experienced practice nurse, classroom training is complemented by work-based learning supported by Clinical Mentors. In-house clinical staff, including senior nurses, GPs and Practice Managers provide further support and training. Nurses spend 30 hours a week in practice including approximately 7.5 hours per week of protected learning time in addition to university study days with their mentor and a peer support tutorial group. Students used portfolios for guidance and reflection. Practices receive salary support for the trainees during their training. The programme provides training modules in core clinical skills as follows:

- Cervical Cytology

- Family Planning and Sexual Health 
- Coronary Heart Disease Management in primary care

- Diabetes Care

- Asthma and COPD

- Teaching and assessment

- Research Methods

- Philosophy and Politics of Primary Care

Further objectives were exploring nurses' contribution to service provision and quality of care and meeting Quality and Outcomes Framework (QOF) indicators in the surgeries they worked. QOF provides financial rewards to general practices for the provision of high quality care, though voluntary most practices choose to participate ${ }^{[18]}$.

This research was undertaken as a programme evaluation and ethical approval gained through the University Research Committee. Ethical research protocols were adhered to throughout.

\section{Methods}

Two qualitative data collection methods (focus groups and semi-structured interviews) were utilised to assess the effectiveness of the programme. The two methods were deployed in an equal and complementary design in order to generate corroborative findings in respect of impact and enrich the data ${ }^{[19]}$.

\subsection{Participants and measures}

At the time of the evaluation 22 students in total had either completed or were studying in the programme. The probability sample of nurses comprised of participants who had completed the programme in the summer of 2010 (45\% of the total first cohort).

Semi-structured, one-to-one telephone interviews with Open Doors nurses $(n=6)$, GPs $(n=4)$ and other practice staff comprising of a Clinical Mentor, three senior nurses and two Practice Managers $(n=6)$ were conducted in a confidential area whilst at their place of work.

A focus group discussion conducted at NHSTH with Practice Nurses who had taken part in the programme (n=6). The focus group was facilitated by the authors and no other educational or health professional staff were present to allow openness and increased confidentiality of participants. One-to-one discussions with NSHTH staff responsible for commissioning, organising and running the programme $(n=3)$.

\subsection{Data analysis}

Data were digitally recorded and transcribed verbatim independently for the telephone interviews and focus group. Data were thematically analysed by the authors'. This flexible approach provided an inductive method to identify rich themes within the data ${ }^{[20]}$. Themes were obtained firstly by familiarisation through reading and rereading of text. Initial codes were then generated and themes highlighted. Themes were then reviewed and refined whilst checking against the original data to ensure their veracity.

\section{Results}

\subsection{Effectiveness and satisfaction}

In telephone interviews, participants were asked: "From your perspective how effective would you rate the Open Doors programme with 1 being 'Very Effective' and 5 'Poor'?” In response, 75\% of interviewees, including GPs, rated the programme as 'very effective' and the remainder as 'effective'. No-one assessed the programme negatively. 
All Open Doors nurses said they would recommend the programme to others as did Practice Managers and GPs and moreover, they would permanently employ the nurses:

"We are looking to employ (this nurse) and in fact I think as a practice we have come for another one." (GP)

It was indicated by all those interviewed that Open Doors met a training need and filled a skills shortage gap:

"I mean at the end of it I think it's produced a very good practice nurse ... the training is certainly an effective way of producing practice nurses". (GP)

"It is something that is needed in this area. It is good for nurses to come in and see what they are getting into ... We are just about to take another Open Door nurse and I really wouldn't get into it if I thought anything negative about the scheme.” (Practice Manager)

"I am very lucky to have got on this course and have the opportunity because I know a lot of nurses struggle over many years to have the education I received through this." (Open Door nurse)

\subsection{Themes}

Nine themes from the qualitative data were identified to indicate the impact of the programme.

\section{Theme 1: Structure of course programme}

Participants valued having a formal, structured, degree level programme to develop nurses in general practice:

"I just think Open Doors gave a really rigid, structured approach that GPs aren't and practice managers aren't ... They're having to follow a structured programme." (Clinical Mentor)

"The way nursing is going into a degree led profession you need the education to do these jobs." (Open Doors nurse)

Open Doors was seen as superior to previous less structured programmes:

"I would argue that it's (Open Doors) better than experience - the old style practice nurse ... could be called a practice nurse after gaining a lot of experience." (GP)

"I had friends who got into practice nursing without doing Open Doors or anything like it. They've had a completely different experience and they've actually left practice nursing.” (Open Doors nurse)

\section{Theme 2: Rapid competency}

Though two participants queried if the programme could be shortened, this view was not held by the other participants. The majority indicated Open Doors a more efficient and quicker way of developing practice nurses.

A key benefit stated was that the modular approach allowed nurses to become competent quickly in specific areas. GPs were confident Open Doors nurses could carry out tasks without close supervision after completing a module.

"I know that they have the theoretical element but then it's the application of it. I think the mentoring aspect also - I thought gave the nurse the support and confidence that she needed to then gain our confidence in following through with what she was learning." (GP) 
"Instead of it taking three or four years to get a nurse to the level that Open Doors gets you to, it only takes two years. In fact less than that, it takes a year before they are really good practice nurses.” (Clinical Mentor)

"Once she's completed a module it gives us confidence that she can work in that area ... that she's safe working in those areas like child immunisation and diabetes care." (GP)

\section{Theme 3: Course content transferability and application}

Positive learning outcomes are linked to both self-efficacy and instrumentality ${ }^{[21]}$. The responses indicate these conditions were met. Open Doors nurses stated for example, if their learning was appropriate for their job:

"It's all the clinical skills and knowledge that I need in my daily work." (Open Doors nurse)

"I think the majority of the modules offered and taken have been really relevant to the practice." (Open Doors nurse)

Open Doors nurses also indicated the value and relevance of the link between classroom and workplace learning supported by mentors.

"Some of the things I had to do as a practice nurse I never had experience of before, things like family planning or chronic heart disease. So it was absolutely necessary to have some sort of training beforehand. It speeded up the whole process - would have taken a lot longer to get to grips with the basics." (Open Doors nurse)

"It's very effective ... the opportunities - having access to all the courses and education and the mentoring system to then be able to back up the education side in practice has been invaluable." (Open Doors nurse)

"If I had had the education without the mentoring sessions and the allocated learning time I don't believe I would have learnt as well or maybe as quickly without being able to come back [to the practice] and back it up with patients with those diseases or conditions." (Open Doors nurse)

\section{Theme 4: Course programme learning blend}

Other interviewees expressed similar views about the effectiveness of the programme and the value of its structure:

"When they have an opportunity to actually have practical experience while they're doing - that is probably a good thing ... from my perspective it has been helpful for the nurse that it was done in that way." (GP)

"With Open Doors because you're being trained in-house and you're getting back up from the university and you're getting a mentor going in who's assessing you and making sure you're working along at - you've been working at a certain speed, it works really well.” (Clinical Mentor)

\section{Theme 5: Peer and mentor support}

The importance of NHSTH employed mentors in the workplace to support guided learning was acknowledged by all the Open Doors nurses.

"Obviously we spend time watching how they work, that probably influences a lot of us, how we work. Not copying but never having experience in certain areas, being able to have someone watch how you do it and point out the right direction is helpful. That's one of the ways the programme's probably helped to improve my patient care." (Open Doors nurse) 
"My Clinical Mentor has been a tremendous support and has been invaluable to my learning and professional needs". (Open Doors nurse)

The Clinical Mentor echoed the nurse’s comments:

"Having an outside mentor come in makes sure the structured approach continues and it also allows the practice nurse a safe person to ask. If at some point they think they are doing something unsafe at least they have somebody to go - 'is that right? Is it something I should be doing?' So for the patient it is providing safe care." (Clinical Mentor)

Open Doors nurses from both the focus group and interviews commented peer support was an important and highly valued support resource. The programme factors in designated time for students to meet as a peer support group.

"I realise how fortunate we have been in having our 'group'. Without them it would have been very lonely and isolating." (Open Doors nurse)

“Invaluable - my first experience of peer support and a very positive one.” (Open Doors nurse)

All participants provided examples of a wide range of areas in which they were working independently, as follows.

- Monitoring patients with chronic lung disease

- Assisting patients and carers with disease management

- Child and adult vaccinations

- Taking smear tests

- Screening programmes

- CHD management including encouraging healthy lifestyles

- Diabetes screening, self-care and prevention of complications

- Family Planning advice

\section{Theme 6: Skills progression}

These roles previously were undertaken by senior nurses and in some cases GPs. It has been indicated in previous research that there is recognition that developments in health, technology and increased emphasis on service users requires education and professional boundaries to be dynamic ${ }^{[22]}$. From the practices' point of view, the key benefit was that they increased capacity and therefore access and quality of care for patients:

"The Open Doors nurse can walk into a job and offer clinics in absolutely anything: chronic disease management, family planning, cervical cytology ... so the more you are able to do as a nurse, the more you are able to provide." (Clinical Mentor)

"Open Doors has improved QOF and [the Open Doors Nurse] took ownership of some chronic disease areas. Nurse access has significantly improved.” (Senior Practice Nurse)

"Their confidence and the quality of their training reflects how they are with patients ... we've received positive feedback in that respect." (GP)

\section{Theme 7: Impact on patient and practice outcomes and services}

Research suggests higher numbers of practice nurses links to better quality patient outcomes ${ }^{[23]}$. From the focus group and interview discussions both GPs and the Open Doors nurses themselves perceived they (the nurses) were able to reduce the workload of others. One GP noted that the Open Doors nurses: 
“... benefited the surgery because they free up time” (GP)

"More appointments are available for patients, because you have that additional nurse which makes a big difference. You could have another thirty appointments each day that they are here. It makes a big impact on the patient service I think.” (Practice Manager)

Open Doors nurses were themselves clear of their impact:

"It's a positive impact because obviously I can reduce the workload off of others. Nurses are seeing a lot more patients with chronic diseases such as diabetes, so we are able to relieve the workload of GPs who can then concentrate on access and emergency appointments." (Open Doors nurse)

"It means that they can see the same nurse regularly instead of seeing a different nurse for each condition. It means you can build up a better relationship with the patient" (Open Doors nurse).

Other participants believed that Open Doors had contributed to improvements in the quality of care:

"You can look at the patient more holistically. Somebody shouldn't be coming in for a blood pressure if they obviously need their asthma checking or they may need a smear test, so it gives you a more wholesome approach to nursing." (Clinical Mentor)

"I think [the Open Doors Nurse] has established a very good rapport with the patients. I haven't heard any complaints. We have heard very good comments about how she deals with patients." (GP)

\section{Theme 8: Recruitment and Retention}

A specific aim of the Open Doors programme was to improve recruitment and retention of practice nurses in the Borough.

In both the interviews and focus groups trainees were asked if they intended to remain working in primary care within Tower Hamlets. All trainees responded positively although none were previously employed in Tower Hamlets.

“This will be my job for the rest of my nursing career.” (Open Doors nurse)

"I don't see myself moving away from it for the foreseeable future." (Open Doors nurse)

A senior nurse indicated why she thought the programme would improve recruitment and retention:

"It is an effective way to develop practice nurse posts. Doing it this way means both nurse and practices have to commit fully and both are aware of the commitment. Therefore staff retention is better and drives up the quality of care for patients." (Senior Practice Nurse)

\section{Theme 9: Adjustment to the development of Open Doors nurses}

Open Doors nurses reported some negativity from other practice staff:

"There's always a little bit of doubt with nurses that have been in place for a long time. Because you think someone's coming in and they're learning and they're more up to date. ” (Open Doors nurse)

"The other nurse in my practice saw it [Open Doors] as a threat and was not very helpful” (Open Doors nurse).

More established nurses, the Open Doors nurses also believed, were concerned that the training they had received themselves was inferior to Open Doors and were as a result, challenged by the programme. 
The Clinical Mentor and one GP also identified this issue and referred to senior nurses "protecting" information. It was considered though as a signal that the training was of a high quality. However, it was also indicated by the Clinical Mentor that this situation was resolving:

"They're learning so quickly, these nurses and they're picking up courses some of the senior nurses cannot get on and haven't got access to. It's more about working together ... I think that the issue has sort of resolved itself slightly because [NHSTH] trained a lot of the senior nurses so they were up to the same standard".

\section{Discussion}

The results from this evaluation suggest this programme is an effective and innovative means of training general practice nurses. It provides trainees with structured, formal, up-to-date and directly relevant knowledge and competence-based learning appropriate to general practice nursing. Through the support of Clinical Mentors and practice staff, 'learning by doing' and 'learning by example', Open Doors nurses are able to generalise, process, reinforce, transfer and apply their classroom learning ${ }^{[24,25]}$.

No participants within the research identified any significant difficulties or barriers to learning on this programme. Whilst occasionally a perception of senior nurses feeling threatened by the trainee's knowledge occurred, it did not appear to inhibit Open Doors nurses' learning. Many senior nurses were indeed positive and supportive of trainees and both trainees and practices reported that they felt they were part of the team.

Following teaching, Open Doors nurses were, with few exceptions able to carry out duties such as child immunisation and cervical cytology. As a result this increased capacity and allowed practices to more readily meet their QOF targets. GPs also reported patients were satisfied with services provided by Open Doors nurses.

Trainees were able become 'part of the machinery' quickly gaining clinical and non- clinical experience of primary care. This in turn relates to a likely increase of nurse retention as most employees who leave a new job do so in the first year of employment ${ }^{[26]}$.

While it was not possible to directly compare Open Doors with other practice nurse training programmes participants believed it to be a more effective, efficient and high quality means of developing nurses in general practice.

Until recently there has been no national recognised job role for practice nurses leading to an ad-hoc development of posts locally. The Open Doors programme establishes a structured set of responsibilities reflecting the latest duties of practice nurses. The degree level of the programme is also seen as a positive means of recruiting nurses into the Borough.

\section{Limitations}

There are some limitations to this research which primarily focused on a small sample within a cohort completing the programme. In addition, for full benefits of the programme to be realised requires evaluation of further cohorts over a longer time span.

\section{Conclusions}

Primary care is undergoing rapid change. Rising demands on services along with healthcare system reform will require a further expansion in the employment of general practice nurses ${ }^{[6]}$. Recent research by the National Nursing Research Unit suggests increasing nursing capacity in general practices is likely to improve performance in a number of clinical areas associated with QOF ${ }^{[23]}$. Building local practice nursing capacity will also potentially provide other benefits including 
reduced recruitment and agency nurse costs. The Open Doors initiative new model of learning maybe transferable to efficiently training practice nurses in other locations.

At present, workforce planning and education is paramount to providing increased primary patient care. As such, results from this evaluation indicate overall that Open Doors as an effective learning programme. If replicated it may provide a positive future model for acquiring and retaining general Practice Nurses who speedily become competent in the appropriate knowledge, skills and aptitude required.

\section{Acknowledgments}

The authors would like to acknowledge Vicky Souster from NHS Tower Hamlets who devised the Open Doors Programme and for facilitating this evaluation.

\section{Competing interests}

This evaluation was funded by NHS Tower Hamlets via London South Bank University and was undertaken and reported by the authors as an independent evaluation.

\section{References}

[1] DoH. White Paper Equity and excellence: Liberating the NHS. 2010. Available from: http://www.dh.gov.uk/en/Publicationsandstatistics/Publications/PublicationsPolicyAndGuidance/DH_117353 (02 May 2012, date last accessed).

[2] McDonald R, Campbell S, Lester H. Practice nurses and the effects of the new general practitioner contract in the English National Health Service: The extension of a professional project. Social Science and Medicine 2009; 68: 1206-1212. PMid:19254819 http://dx.doi.org/10.1016/j.socscimed.2009.01.039

[3] Pearce C, Hunt S, Phillips C. When policy meets the personal: general practice nurses in Australia. Journal of Health Services Research and Policy. 2010; 15(2): 26-33. PMid:20176663 http://dx.doi.org/10.1258/jhsrp.2009.009099

[4] Gregory S, General Practice in England: An overview. The King's Fund 2009.

[5] Maynard A, Scott A. Economic Challenges in Primary Care. In Advances in Health Economics. A.Scott, A.Maynard, A. Elliot, ed. Chichester : John Wiley \& Sons. 2003: 187-204.

[6] Kings College, Do we need more practice nurses? Policy+ Issue 23. Kings College London 2010.

[7] NHS Tower Hamlets, Strategic Plan: 2009/10-2012/13. 2009. Available from: www.towerhamlets.nhs.uk\%2FEasySiteWeb\%2Fgetresource.axd\%3FAssetID\%3D685\%26type\%3Dfull\%26servicetype\%3D... \&ei=iuDBUI3CFpLP4QTNzIG4Ag\&usg=AFQjCNG2MDADwPdmh6fTDNCMYKbNbW5ppw (20 May 2012, date last accessed).

[8] Data Management and Analysis Group, GLA Social Exclusion Update, DMAG Briefing. 2008-30. 2008. Available from: www.legacy.london.gov.uk/gla/publications/.../dmag-briefing-index.pdf (02 May 2012, date last accessed).

[9] GLA, Greater London Authority Round Demographic Projections (DMAG Briefing 2008-07). 2007. Available from: www. legacy.london.gov.uk (20 May 2012, date last accessed).

[10] Tower Hamlets, Time for health. The annual report of the joint director of public health, 2008-09. 2009. Available from: www.towerhamlets.nhs.uk (20 May 2012, date last accessed).

[11] Health profile, Tower Hamlets. 2009. Available from: http://www.thpct.nhs.uk/(20 May 2012, date last accessed).

[12] HNACP. Health Needs Assessment for Commissioning Strategy Plan. 2008-09. 2008. Available from: http://www.towerhamlets.nhs.uk/publications/corporate-publications/?entryid4=2266\&p=3 (20 May 2012, date last accessed).

[13] DH, Our Health, Our Care, Our Say. London: Department of Health. 2006. Available from: http://www.dh.gov.uk/assetRoot/04/12/74/59/04127459.pdf (20 May 2012, date last accessed).

[14] O'Donnell C A, Jabareen H, Watt G C M. Practice nurses' workload, career intentions and the impact of professional isolation: A cross-sectional survey. BMC Nursing. 2010; 9: 2. PMid:20205777 http://dx.doi.org/10.1186/1472-6955-9-2

[15] Gould D, Berridge E-J, Kelly D. The National Health Service Knowledge and Skills Framework and its implications for continuing professional development in nursing. Nurse Education Today. 2007; 27(1): 26-34. PMid:16616397 http://dx.doi.org/10.1016/j.nedt.2006.02.006 
[16] RCN data assets, 2010. Available from: http://www.rcn.org.uk/_data/assets/pdf_file/0004/176431/Unit3-Generic.pdf (20 May 2012, date last accessed).

[17] Laurent M, Reeves D, Hermens R, Braspenning J, Grol R, Sibbald, B. Substitution of Doctors by Nurses in Primary Care. Cochrane Database of Systematic Reviews. 2004; 4:CD001271.

[18] The Quality and Outcomes Framework. The NHS Information Centre. 2011. Available from: http://www.ic.nhs.uk/statistics-and-data-collections/audits-and-performance/the-quality-and-outcomes-framework (20 May 2012, date last accessed).

[19] Lambert S D, Loiselle C G. Combining individual interviews and focus groups to enhance data richness. Journal of Advanced Nursing. 2008; 62(2): 228-237. PMid:18394035 http://dx.doi.org/10.1111/j.1365-2648.2007.04559.x

[20] Braun V, Clarke V. Using thematic analysis in psychology. Qualitative Research in Psychology. 2006; 3: 77-101. http://dx.doi.org/10.1191/1478088706qp063oa

[21] Chiaburu D, Lindsay D. Can do or will do? The importance of self-efficacy and instrumentality for training transfer. Human Resource Development International. 2008; 11(2): 199-206. http://dx.doi.org/10.1080/13678860801933004

[22] Nancarrow S A, Borthwick A M. Dynamic professional boundaries in the healthcare workforce. Sociology of Health \& Illness. 2005; 27(7): 897-919. PMid:16313522 http://dx.doi.org/10.1111/j.1467-9566.2005.00463.x

[23] Griffiths P, Murrells T, Maben J, Jones S, Ashworth M. Nurse staffing and the quality of care in UK general practice. British Journal of General Practice. 2010; 60(2): 34-39.

[24] Baldwin T T, Ford K J. Transfer of training: A review and directions for future research. Personnel Psychology. 1988 ; $41: 63-105$. http://dx.doi.org/10.1111/j.1744-6570.1988.tb00632.x

[25] Burke L, Hutchins H. Training Transfer. Human Resource Development Review. 2007; 6(3): 263-296. http://dx.doi.org/10.1177/1534484307303035

[26] ACAS. Recruitment and induction booklet. October 2007. Available from: http://www.acas.org.uk/CHttpHandler.ashx?id=268\&p=0 (20 May 2012, date last accessed). 